\title{
Salud urbana y morbilidad urbana: efecto del caos de los medios de producción en la ciudad capitalista
}

\author{
Urban health and urban morbidity: the effect of the chaos \\ of the means of production on the capitalist city
}

Giovanni Marlon Montes Mata [I] Rafael Monroy Ortiz [II]

\begin{abstract}
Resumen
La ciudad capitalista es dibujada con bolígrafos privados, cuyos trazos de apropiación describen un caos de los medios de producción. En el capitalismo edificado, el caos no solo permite la asignación de espacios materiales a cada actividad productiva bajo principios de "producción, distribución y acumulación", sino que la morfología urbana de extracción de plusvalía o renta se resignifica en "extracción/contaminación y fragmentación/ destrucción", considerando solo externamente la salud ambiental y humana. Por tanto, para discutir críticamente el funcionamiento de la ciudad se propone la categoría teórica caos de los medios de producción, asumiendo que la morbilidad urbana es una condición predeterminada de la ciudad capitalista que le confiere el status de fundamental para su reproducción.
\end{abstract}

Palabras clave: ciudad capitalista; salud urbana; morbilidad urbana; caos; medios de producción.

\begin{abstract}
The capitalist city is drawn with private pens, whose appropriation lines describe a chaos of the means of production. In built capitalism, chaos not only allows the allocation of material spaces to each productive activity under the principles of "production, distribution and accumulation", but also the urban morphology of extraction of surplus value or rent is re-signified into "extraction/contamination and fragmentation/ destruction", considering environmental and human health only externally. Therefore, to critically discuss the functioning of the city, the theoretical category chaos of the means of production is proposed, assuming that urban morbidity is a predetermined condition of the capitalist city that grants it the status of fundamental for its reproduction.
\end{abstract}

Keywords: capitalist city; urban health; urban morbidity; chaos; means of production. 


\section{Boceto teórico de la ciudad capitalista y sus componentes}

Algunos personajes reconocidos describen de forma diferenciada el desarrollo económico histórico como una secuencia de fases: Adam Smith señala que estas corresponden a la caza, la crianza, la agricultura, el comercio y la industria; Friedrich List las desglosa en esclavitud, actividad pastoril, agricultura, manufactura y el comercio; por otro lado, Karl Marx establece una teoría que se basa en una secuencia a partir de la apropiación de los medios de producción (capital, tierra y trabajo) definidas como comunismo primitivo, esclavismo, feudalismo y capitalismo. Son estos esbozos teóricos, los mismos que facilitaron la interpretación del papel de los indicadores que forman parte del desarrollo económico de la humanidad y el desarrollo intrínseco de la ciudad en cada etapa civilizatoria, pero es esta última clasificación la que trazó un esquema de progreso de las comunidades pre y post industriales; si bien cada etapa ha sido diferenciada, el pistón que incita el cambio de modelo productivo a otro, así como el proceso de germinación de distintas morfologías urbanas, ha sido la existencia y persistencia de factores que crean un excedente de producción permanente u ocasional apropiado por una minoría, permitiendo patrones de consumo elevados y la necesidad de intercambio con otras comunidades más o menos desarrolladas. Dicho intercambio permite mayor especialización y división del trabajo, mayor acumulación de riquezas, e incorporación de los recursos naturales al proceso productivo, maniobras que se sintetizan conceptualmente en "producción, distribución y acumulación", ligados a la construcción de un espacio urbano para la "acción, interacción y ejecución", pero teniendo en el fondo del esbozo la "extracción/ contaminación, fragmentación y destrucción" (Furtado, 2014, pp. 127-228).

Asimismo, el desarrollo de las sociedades se forjó gracias a periodos importantes de esclavitud y guerras, aberraciones para la apropiación de la fuerza de trabajo y tajadas de territorio, siendo el transporte y las comunicaciones la llave que impedía o permitía el progreso. Si bien, entrañables efectos ambientales y sociales de la actual racionalidad económica denominadas "externalidades" (O'Connor, 1998, p. 193) ya estaban presentes en el feudalismo (economía comercial que no solo se concedió una expansión territorial importante sino la formación de una nueva clase social, la burguesía), es con el régimen de laissez-faire (régimen que brindó la oportunidad de la liquidación del débil por los más fuertes mediante la competencia en los mercados y dominación de las operaciones del comercio exterior) que se bosqueja el surgimiento del capitalismo industrial y con ello impactos socio-ambientales inconmensurables (Furtado, 2014). Dicha transición se da a partir de la tensión en el comercio europeo por la competencia y el costo de producción; comienzan a surgir fábricas que tienen como objetivo intensificar el uso de los instrumentos de trabajo, perfeccionar las técnicas de producción, controlar el número de horas trabajadas y aumentar la tasa de aprovechamiento de las materias primas, pero al mismo tiempo son factores que dibujaron el espacio urbano que 
poco a poco va configurando las primeras ciudades capitalistas como un proceso de metamorfosis urbana, hasta completar su fase en un cuerpo físico tangible que les permita acumular riquezas con facilidad.

La consolidación de dicha racionalidad económica vislumbra un fenómeno donde el hombre ha cambiado su entorno en la faz de la tierra como ningún otro, proceso que ha sucedido de manera acelerada y en un lapso de tiempo corto ( $5 \%$ de la humanidad desde la aparición de las primeras civilizaciones), trayendo consigo oleadas de extinción de especies, contaminación del aire, agua y suelo, así como calentamiento global entre los más importantes (Sartelli, 2013; Harvey, 2012). El ente urbano capitalista ha sido la materialización de dicha racionalidad, reconocida como su máxima expresión (Sartelli, 2013), que permite una transfiguración que asigna a cada actividad espacios materiales construidos, hasta otorgarle un cuerpo tangible, igual a una obra de arte que expresa el aprovechamiento de los recursos naturales y que erige monumentos a la explotación de la mano de obra. En otras palabras, la morfología de cualquier cuerpo urbano capitalista o el diseño mismo de alguna extremidad urbana, corresponden a los principios de "producción, distribución y acumulación", que seducen a toda una ciencia urbanística-arquitectónica que también es embestida por los grandes capitales, o que a menudo se deja llevar por el oleaje del poder económico.

En 1971 Manuel de Sola-Morales elaboró una teoría de la estructura urbana, definiendo elementos de forma (edificaciones, parcelas, calles e infraestructuras) y mecanismos de actuación, construcción, propiedad, uso y transformación en el tiempo, siendo la combinación de estas categorías las que dan lugar a la morfología urbana, e incluso reconociendo tipologías urbanísticas como los ensanches, las hileras urbanas, la urbanización marginal, la ciudad jardín y los polígonos de viviendas. Asimismo, Gianfranco Caniggia a principios de los años 70 s, entendía la ciudad como un organismo resultante de la suma de componentes que conforman estructuras más complejas, desde la casa-vivienda, edificaciones especializadas, agrupaciones en manzanas (módulo inherente de lo urbano), clasificación del tejido urbano (vías fundamentales, vías secundarias, y vías de conexión), hasta completar la ciudad u otras estructuras superiores (Capel, 2002, pp. 49-50). Del mismo modo, Fernand Braudel en 1967 manifiesta que las formas urbanas tienen una duración diferenciada (larga, media, corta), debido principalmente a las fuerzas ambientales y culturales que influyen en las afectaciones urbanas en el tiempo y el espacio. Aldo Rossi y Georges Chabot comprendían de forma semejante la estructura de la ciudad desde la autonomía acogida por un marco socio-económico y su entendimiento desde las formas, así como desde la geografía regional, una perspectiva que atiende los lugares específicos y la historia. Algunas otras categorizaciones de la morfología urbana contemporánea la definen desde la composición del plano ortogonal, particularmente con las calles, las manzanas, las edificaciones y las parcelas (Capel, 2002, p. 198). La ciudad actual también se comprende como un cuerpo orgánico donde no solo impera la forma sino en fondo, subdividida en usos de suelo, vialidades, espacios verdes o parcelas, equipamiento urbano, soporte infraestructura 
y servicios básicos. Incluso, si bien resulta complejo agrupar de forma compacta las múltiples ciudades del planeta, hay quienes establecen que de acuerdo a la mezcla de rasgos urbanos con aspectos sociales, culturales, ambientales y económicos, estas se pueden categorizar de la siguiente forma: ciudades de Europa (Europa central y Occidental, Mediterráneas y Europa oriental); ciudades de la URSS (Rusia tradicional y Asia soviética); ciudades de África; ciudades de Australia; ciudades del Norte de Asia y Asia periférica (Asia septentrional, Sur y Sureste Asiático, Oriente medio y Extremo Oriente); y por último ciudades de América (Capel, 2002, pp. 49-67). Particularmente, la composición de las ciudades de Europa y América a partir del siglo XIX se debe en gran medida a la réplica de los trabajos de Haussmann en Paris, aquellos que entrañaban reformas autoritarias y antidemocráticas que expulsaban del centro de la ciudad a las clases sociales populares (Capel, 2002, p. 374).

A pesar que la ciudad contemporánea se vista y maquille con multifacéticas formas urbanísticas y arquitectónicas, o se localice en distintos hemisferios geopolíticos, siempre que se discutan los componentes estructurales o particulares de lo urbano, implícitamente se entrañan conceptos teóricos para la acumulación de la riqueza; los asentamientos irregulares plagados de un ejército de reserva en condiciones de miseria y pobreza (agudizados en el sur geopolítico), son necesarios porque poseen abundante fuerza de trabajo (jugosa mercancía ficticia susceptible de ser succionada) que en cierta porción se convertirá en plusvalía; el tejido urbano expresado en vías de comunicación (primaria, secundaria o terciaria) dentro de la ciudad o entre ciudades, son resultado de un proceso donde los distintos medios productivos tienen que interrelacionarse y adecuarse a las necesidades del mercado mundial, siendo los pueblos más alejados los que carecen de interconexión, a menos que cumplan un papel importante que genere ganancias; la fragmentación del territorio en usos de suelo alude a la división de clases sociales, pues forma parte de una distribución desigual y heterogénea, dando señales claras de quien es el subordinador y quien el subordinado, por lo que resulta necesario mantener los más altos índices de marginación o rezago social, hasta orillar a sus residentes a aceptar condiciones de trabajo que mantengan latente su condición de pobreza; las agrupaciones de viviendas en los diferentes usos de suelo son un indicador de quien posee dos o hasta tres medios de producción (capital, tierra y trabajo) y por el contrario, quien solo posee uno (trabajo), para obtener una remuneración que satisfaga su condición de miseria permanente; las infraestructuras y el equipamiento urbano también son desiguales y hasta dictatoriales, pues las viviendas emplazadas en los usos de suelo con mayor densidad poblacional sufren de discriminación urbana, ya que no cuentan con los servicios básicos para la subsistencia (no hay agua potable y cuando la hay, está contaminada; no hay luz eléctrica y cuando la hay, los usuarios no pueden pagarla; no hay drenaje y cuando lo hay, su contenido va a los cuerpos de agua superficial sin tratamiento; no hay servicios de salud y cuando los hay, estos no son suficientes ni eficientes; no hay escuelas y cuando las hay, los niños acuden sin comer, sin zapatos, sin útiles, o en algunos casos no acuden por su extrema pobreza; no hay parques y cuando los 
hay, están abandonados y parecen refugios de la delincuencia; no hay recolección de residuos y cuando la hay, no se les otorga tratamiento y solo se les traslada y dispone en algún lugar donde sea permisible contaminar).

A pesar que el límite de aprovechamiento de la naturaleza y la mano de obra son la base de reproducción del capital, también atentan contra su propio modo de reproducción, consideradas "contradicciones del capitalismo". En este sentido, si bien el análisis de la evolución de las formas urbanas es preponderante, sino no se discuten desde sus profundos aspectos estructurales, y por el contrario, las formas se suman a la explotación de los medios de producción hasta su límite, estos mismos se convertirán en paradojas que eventualmente tomarán forma de amenazas civilizatorias (O'Connor, 1998; Harvey, 2012). De hecho, el "ejército de reserva" no solo funciona como mano de obra barata y potencial consumidor, sino que tal excedente de población configura la nueva geografía urbana teñida de múltiples aspectos, ya que la gente tiene que vivir en algún lugar y de alguna forma, por lo que se construyen paisajes humanos con diferencias geográficas, en las que intervienen las relaciones sociales, los sistemas de producción, los estilos de vida, las tecnologías, formas organizativas y las relaciones con la naturaleza. No obstante, las esferas de productividad se caracterizan por la falta de armonía con distinción de clases urbanas, materializadas en asentamientos irregulares o si se prefiere, lugar donde vive una cantidad importante de fuerza de trabajo amontonada de manera ilegal. Es entonces que el capital expresa su poder en el territorio, emplazado en la proximidad de los medios de producción; el caos que provoca la diferenciación geográfica es el primer paso para que comience la acumulación de capital, por lo que la diversidad geográfica se vuelve una condición necesaria para esta acumulación, y si el caos no existe, debe crearse (Harvey, 2012, pp. 133-136).

En general, la producción y reproducción del espacio (urbanización), es el gran negocio del capitalismo por ser la máxima vía de acumulación de riqueza; si bien la urbanización intenta ser la solución al problema entre el excedente de población y capital, al funcionar como un instrumento de estabilización social, ya que entre más se construye, la cantidad de empleos aumenta, en infinidad de ocasiones poco importa devorarse todo un ecosistema para seguir construyendo nuevas formas de espacio urbano. Vastos proyectos infraestructurales sin duda están trasformando el paisaje y las condiciones de vida, algunas veces generando condiciones directas e indirectas de enfermedad o muerte; de hecho, la absorción del excedente mediante la urbanización tiene un lado nada luminoso, y esto se refiere a la "destrucción creativa del territorio", abriéndole camino a una "segunda naturaleza” (Harvey, 2012, pp. 155-156).

\section{Caos de los medios de producción}

La acumulación de la riqueza en la esfera capitalista depende de un requisito imprescindible, la construcción de un espacio urbano y no tan urbano construido por el hombre para la conjugación del capital con los recursos naturales y la fuerza de trabajo. De hecho, en el ente urbano insaciable, el capital 
creará las condiciones para la explotación de los medios productivos (capital, tierra y trabajo), sin importar que el trabajador y las materias primas representen barreras causantes de inestabilidad o pérdidas monetarias ante el mismo desarrollo económico.

\section{Breve descripción del caos del capital}

La lógica de acumulación capitalista ya había estampado su huella hasta el rincón más remoto del planeta para 1900; no había región que no fuera o haya sido afectada por el impacto de este modelo de producción. Incluso, la adopción de esta formación económica ha transformando la ideología de la sociedad y en poco tiempo es un comportamiento que forma parte de la naturaleza humana (Hartman, 2008 , p. 359). En la economía capitalista, las utilidades son tanto el medio como el fin; el capital en expansión se plasma cuando los capitales individuales usan las actividades productivas para generar más utilidades, lo que sin duda se vuelve una lógica de "dinero en busca de más dinero" (O'Connor, 1998, p. 217). Teóricamente el capital existe bajo la forma simple del dinero, y el capital que existe bajo la forma del dinero, no es estático pues necesita de la libre circulación. Para ello, el dinero toma forma de mercancía y la mercancía como dinero, sin que en el proceso de circulación se pierda valor alguno. En sí mismo, el dinero como mercancía o dinero, sigue expresando el valor monetario, o valor de cambio que entraña cualquier mercancía (Marx, 2008, pp. 273-274). En definición, el capital es la valorización del valor, y en todo caso la permanencia del valor que circula en todos quienes portan valor: por lo que la propiedad privada perteneciente al propietario del valor, es quien asegura su permeancia en el tiempo (Dussel, 2014, p. 77). El sujeto propietario del valor, es el sujeto articulador de las "determinaciones" (portadoras del valor) para la creación del capital: dinero, medio de producción, trabajo, producto y mercancía (Dussel, 2014, pp. 77-80).

El proceso resultante es una espiral ascendente creciente, que suma y multiplica las determinaciones. Dicho proceso inicia cuando el dinero deja de existir, al transformarse o comprar medios de producción, o transformarse en salario del trabajo. El proceso de trabajo se vuelve objeto o producto (el medio de producción es la materia presente en el producto y el trabajo es el valor del producto). Después, el producto es puesto a circular en el mercado, donde se niega como producto y toma la forma de mercancía. Por último, con la venta de la mercancía, el circulo ascendente se cierra pues el valor de la mercancía se trasforma en el dinero inicial, dejando la ganancia o excedente que pudo extraerse. En definitiva, el capital es dicho proceso circulante acumulativo, siendo el valor el único que se encuentra presente en todo el proceso, un proceso de valorización del capital (Dussel, 2014, pp. 80-81). Si bien la concentración y acumulación del capital deriva de un proceso rotatorio incesante del valor, es preciso señalar que dicho valor no nace de la nada, sino que procede del efecto de extracción de plusvalía del valor del trabajo que no se remunera. En otras palabras, la plusvalía del proceso rotatorio del valor, es resultado del valor del "trabajo y tiempo de trabajo adicional". En síntesis, el capital no es la suma de las determinaciones, ni siquiera es el dinero, sino que está mejor definido como 
el "movimiento ontológico del valor que se valoriza", es decir, el aumento continuo del valor, por efecto de la acumulación y valorización continua del "plus trabajo".

Sin embargo, para que esta maquinaria acumulativa opere, se multiplique y expanda, es necesaria la apropiación de los medios de producción (tierra y trabajo), proceso indispensable para la construcción del capital; en este sentido, el sector dominante se apropia de los medios de producción para ejercer su dominio y poder, subordinando a la fuerza de trabajo y obteniendo beneficios de los recursos gratuitos que provee la naturaleza (Sartelli, 2013, p. 56). En dicho proceso, estas fuerzas productivas funcionan siempre y cuando se efectivice el proceso de división social, separando personas en funciones de mando y otras de obediencia, es decir, la "lucha de clases", y lo que se puede o no hacer, queda determinado por las fuerzas productivas, pero principalmente por los intereses de las clases sociales dominantes (Sartelli, 2013, p. 53). Tal dominación se ve expresada en la medida que el capital acumula respondiendo a la dinámica del mercado, hasta concentrar poder económico en unos pocos, y generar efectos perversos que tienden a crear y aumentar desigualdades e inequidades (Bifani, 1997, pp. 25-110). Y no porque las inequidades o desigualdades sean una imperfección en la maquinaria económica capitalista, puede afirmarse incluso, que mientras más desigualdades existan, será perfecto el mercado (Piketty, 2014, p. 39.)

Particularmente, si bien el periodo de la revolución industrial hasta el siglo XXI ha traído desbordante acumulación de capital, entraña distribución desigual de las riquezas, concentrando el excedente en una minoría; se estima que para el año 2010, la riqueza de 3,500 millones de personas (la mitad de la población mundial) se concentraba en tan solo 388 personas, y para los años 2011, 2012, 2013, 2014 y 2015, ya se centralizaba en 177, 159, 92, 80 y 62 personas respectivamente; esto significó que para 2015, el $1 \%$ de la población del planeta ya era más rica que todos los seres humanos juntos (Pontón, 2017, pp. 15-16). Asimismo, se calcula que la tasa de producción mundial (promedio anual) de 1700 a 2012 fue de $1.6 \%$, pero de 1913 a 2012 la tasa fue de $3.0 \%$; asimismo, se estima que la tasa de crecimiento del PIB mundial en el periodo de 1700 al 2012 fue de $1.6 \%$ promedio anual, del cual $0.8 \%$ se debió al incremento poblacional y el otro $0.8 \%$ al incremento de la producción por habitante (si bien un incremento del 1\% anual, tanto poblacional como producción per capita puede parecer despreciable, comparados con periodos inferiores con tasas de crecimiento de $0.06 \%$ de la población y $0.02 \%$ en la producción por habitante resulta mayor, pero exponencial cuando la tasa de crecimiento acumulado de $1 \%$ anual, sostenido durante 30 años corresponde a un incremento de 35\%) (Piketty, 2014, p. 83); incluso, en términos de la correlación entre la generación de capital y la ciudad, se estima que el $54 \%$ de la población urbana actual, basta para representar más del $80 \%$ del PIB mundial, acumulado en una minoría (ONUHabitat, 2016, p. 31). Dicho proceso histórico de acumulación, representa al mismo tiempo una profunda desigualdad histórica, llena de inequidades, miseria, morbilidad y hasta muerte (situación que se agudiza en el ámbito urbano). En Noviembre del 2002 se aprobó la resolución de la Asamblea General de jefes de estado y de gobierno, llamada "declaración del 
milenio", la cual destaca el valor de la igualdad, donde ningún individuo o nación se le niegue la oportunidad de beneficiarse del desarrollo, garantizando derechos y oportunidades para hombres y mujeres hacia el año 2015, claramente, los discursos, casi nunca se vuelven hechos (Pontón, 2017, p. 15).

Pero, "como al león por sus garras", al capitalismo se le reconoce inmediatamente por la desigualdad que lo caracteriza. Parece que ahora de lo que se trata es de cortarle las garras al león... para que le vuelvan a crecer más fuertes. (Pontón, 2017, p. 16)

La tremenda desigualdad derivada de la no-distribución de la riqueza, ha empeorado las peores condiciones de los otros que no acumulan; en los últimos años, el $10 \%$ de la población mundial solo registró un aumento en su salario de menos de 3 dólares al año en sus ingresos, y el Coeficiente de Gini alcanzó una desigualdad media mundial de 62, teniendo como desigualdad máxima 100 (Pontón, 2016, p. 15); asimismo, la tasa de desempleo mundial en 2015 era de $5.8 \%$, equivalente a 197.1 millones de personas, siendo 1 millón más que el año 2014 (ONU-Habitat, 2016, p. 34); también se calcula que el $10 \%$ de la población mundial vivía con menos de 1.90 dólares al día en 2015, pero por efecto de la Covid-19, se calcula que en 2020 entre 60 y 40 millones de personas más caerá en pobreza extrema viviendo con menos de 1.90 dólares al día (Banco Mundial, 2020a). Es así que el caos del capital provoca caos en los otros medios de producción (tierra y trabajo) significando, entre otras cosas, presionar la salud misma de toda una civilización que se encuentra subsumida en un modelo productivo que por excelencia es paradójicamente sano, e irónicamente enfermo.

\section{Breve descripción del caos de las condiciones naturales}

Los recursos naturales o "condiciones naturales" al igual que la fuerza de trabajo, no tienen un valor de cambio más si un valor de uso, por lo que se les denomina mercancías ficticias, a pesar que estas condiciones no son producidas de manera capitalista, aunque son compradas y vendidas como si lo fuesen. Las condiciones naturales son determinantes de la dinámica y acumulación del capital, ya que favorecen el aumento de la productividad del trabajo y reducción del valor de cambio de las mercancías, que a su vez incrementan la producción del valor excedente y la utilidad (Marx, 2000). Teóricamente, si la economía se encuentra en expansión, la demanda de materias primas aumentará (siempre y cuando las demás condiciones permanezcan contantes). Si esto sucede, el aumento en la demanda de materias primas y su respectiva explotación elevará proporcionalmente los costos promedio, deprimiendo las tasas de utilidad y acumulación. Al no haber suficiente utilidad y acumulación, los capitales individuales o colectivos intentarán superar dicho cuello de botella invirtiendo en equipo, tecnología e infraestructura para explotar nuevas fuentes de recursos naturales, encontrando mejores formas de aprovecharlos a bajo costo. Paradójicamente, al existir nuevamente beneficios crecientes y acumulativos soportados por menores costos promedio y mayores niveles de producción y uso, los costos y precios del mercado disminuirán, aumentando la tasa de utilidad, acelerando la velocidad de explotación de las materias primas y acumulación de capital, cerrando nuevamente el ciclo con una economía en expansión (O’Connor, 1998). 
[...] las altas tasas de beneficio llevan a altas tasas de acumulación, las que a su vez llevan a una mayor demanda de materias primas; los niveles más altos de explotación de las materias primas crean costos de producción más bajos cuyos resultados son tasas de utilidad más altas todavía. En pocas palabras, si las materias primas son baratas las tasas de acumulación y agotamiento de recursos serán relativamente altas; si las materias primas son caras, se harán inversiones de capital para reducir su costo o a fin de desarrollar formas de utilizarlas más eficientemente. (O'Connor, 1998, p. 217)

Por lo tanto, si no se interrumpe la dinámica expansiva de acumulación de capital, serán más altas las tasas de agotamiento de recursos naturales, así como la generación de residuos contaminantes.

La naturaleza es un punto de partida para el capital pero no suele ser un punto de regreso. La naturaleza es un grifo económico y también un sumidero, pero un grifo que puede secarse y un sumidero que puede taparse. La naturaleza, como grifo, ha sido más o menos capitalizada; la naturaleza como sumidero está más o menos no capitalizada. El grifo es casi siempre propiedad privada; el sumidero suele ser propiedad común. El grifo es, evidentemente, una metáfora del agotamiento de recursos; el sumidero lo es de la contaminación. (O'Connor, 1998, p. 221)

El resultado de dicha racionalidad irracional es un "desarrollo desigual" y combinado, tendiendo hacia un desequilibrio entre mercado y naturaleza; el desarrollo desigual en términos del aprovechamiento de los recursos naturales se refiere a las distintas formas de agotamiento, contaminación y a la posibilidad de un "desarrollo combinado". En otras palabras, el desarrollo desigual significa que el capital industrial, financiero y comercial tiene patrones de acumulación crecientes, extensivos y con mayor poder político, incrementando los impactos negativos en el ambiente gracias a la diferenciación de clases de los hemisferios geopolíticos. Algunas regiones del hemisferio norte cuentan con mayor capacidad económica (resultado de una brutal "acumulación originaria"), convirtiéndolos en potencias industriales a costa de la disponibilidad de recursos en el resto del planeta, quienes en todo caso son víctimas de dicha racionalidad (O'Connor, 1998, pp. 224-227). Además, en la economía capitalista la naturaleza es considerada la base material de la producción, pero no un punto de retorno, por lo que el proceso de producción arroja desechos que se convierten en contaminación peligrosa. Paradójicamente, los subproductos indeseados tienen el efecto de agotar los recursos naturales; por ejemplo, la sobreexplotación y producción de petróleo agota los recursos fósiles, aunque en el proceso, el petróleo se convierte en productos petroquímicos dañinos para el ser humano y la naturaleza misma. La extracción de uranio agota los recursos y afecta la salud de los mineros, al mismo tiempo que trae consigo directa o indirectamente más contaminación. En otras palabras, cuanto mayor sea la tasa de utilidad y acumulación, mayor será la contaminación directa y mayor el agotamiento indirecto de los recursos (Marx, 2000). Este proceso se define a través del desarrollo combinado, donde los recursos naturales se agotan indirectamente como resultado de la contaminación, y a la inversa, la contaminación es un resultado indirecto del agotamiento de 
los recursos. En este sentido, los desechos también llamados subproductos de la industria y del consumo, tienen una concentración espacial, convirtiéndose tarde o temprano en contaminación potencialmente nociva tanto para el ser humano como para los recursos naturales (O‘Connor, 1998).

Esto significa que a pesar que al capitalismo se le atribuye $5 \%$ del tiempo en el desarrollo de la humanidad, sus avances tecnológicos han sido responsables de los mayores daños al ambiente desde la aparición del hombre en la tierra (Sartelli, 2013); entre los principales daños registrados en esta etapa de la humanidad, destacan la reducción de la masa forestal mundial en un $40 \%$ de la cubierta original, mientras que desde 1900 se han destruido $50 \%$ de los humedales del planeta, así como 35\% de los manglares y $30 \%$ de los arrecifes de coral. Incluso, se reconoce que $30 \%$ de las especies del planeta se encuentran en peligro de extinción (WWF, 2016), y en un lapso de 42 años, entre 1970 y 2012 , el tamaño de las poblaciones de vertebrados se redujo $58 \%$, presentando una disminución al año de $2 \%$. También entre 1970 y 2012, el Informe Planeta Vivo (IPV) registró que las poblaciones terrestres disminuyeron $38 \%$ y $81 \%$ en el sistema de agua dulce con las poblaciones monitoreadas (WWF, 2016). Es así que el capitalismo solo va en direcciones ecológicamente insostenibles, sustituyendo cualquier recurso por otro que sea igualmente redituable, sin importar agotarlo o contaminarlo (Harvey, 2012). El mundo del capital no se interesa en el cuidado y preservación de la naturaleza, puesto que las actividades al servicio del medio ambiente no tienen fin de lucro, ni generan ganancias (Tanuro, 2013).
Agua

Particularmente y debido al funcionamiento de la ciudad capitalista y la expansión urbana misma, los patrones de consumo y contaminación del agua se han intensificado y diversificado de forma tan exponencial que representan daños para la sociedad y el ambiente. Se estima que desde 1900 se han extraído $248,000 \mathrm{~km}^{3}$, equivalente a 198 veces el agua de los ríos del planeta o 2 veces el agua de los lagos del mundo (U.S. Geological Survey, 2017; FAO, 2016); además que $80 \%$ de las aguas residuales no reciben tratamiento antes de verterlas a cualquier fuente natural incluyendo ríos, barrancas y el mar, alcanzando 95\% en algunos países subdesarrollados, sin importar que estas contengan virus, bacterias, parásitos o químicos tóxicos. Concretamente, los países de "ingresos altos" tratan arriba del $70 \%$ de sus desechos líquidos, mientras que en los países de "ingresos medios-altos" la cifra se reduce a $38 \%$ y cae hasta $28 \%$ en los países "medios-bajos". Como es costumbre, solo $8 \%$ de las aguas residuales industriales y municipales de los países con "bajos ingresos" se someten a algún tipo de tratamiento (Unwater, 2017).

Para el caso de los países subdesarrollados es práctica común verter aguas residuales sin tratamiento alguno hacia fuentes superficiales de agua, debido entre otras cosas a la falta de infraestructura, capacidad técnica, institucional y sin el financiamiento necesario, pero sobre todo resultado de un ente urbano enfermo que convulsiona (Unwater, 2017). Si bien algunos países reportan porcentajes altos en términos de infraestructura de drenaje, esta solo funciona como un canal de trasporte que 
colecta y dirige los efluentes residuales hacia alguna fuente natural, sin que esto signifique tratamiento adecuado; en el mejor de los escenarios, el agua contaminada se colecta en plantas de tratamiento que no operan por los altos costos energéticos, pues no fueron pensadas para las características del Sur geopolítico, pero que de forma absurda necesitaron inversiones millonarias por su emplazamiento para solo verter su contenido ilegalmente hacia algún cuerpo de agua superficial, a fin y al cabo "para eso están los ríos", sin tomar en cuenta que el ser humano no puede ser saludable, si vive en un ambiente enfermo (Lebel, 2005).

Últimamente, la gestión en torno al cuidado del agua solo involucra al proceso de extracción y consumo del recurso, mas no contemple su desecho. Hay un status de indiferencia relacionado al destino del agua una vez que esta ha sido utilizada, pues en términos generales, hay poca y casi nula existencia de información respecto al residuo líquido urbano contaminante, sin que sea relevante pertenecer a un país desarrollado o subdesarrollado; según ONU, de 181 países analizados para la elaboración del Informe Mundial del Agua 2017, solo 55 tenían información confiable e incluso, algunos de estos datos se encontraban desactualizados (Un Water, 2017). Si bien la ausencia de tratamiento de las aguas residuales es un grave problema, lo es más aun cuando 748 millones de personas no disponen de agua de calidad y 2,500 millones no cuentan con instalaciones adecuadas de saneamiento, desquebrajando el derecho al agua, la salud y al mismo tiempo sentenciando la vida misma (Un Water, 2015), pues en correlación con la salud pública y derivado de un saneamiento deficiente, se evidencia una alta correlación con enfermedades tropicales desatendidas, incluyendo lombrices intestinales, esquistosomiasis, tracoma, así como cólera, disentería, hepatitis $A$, fiebre tifoidea y poliomielitis, adjudicándose la muerte de 1 persona cada 20 segundos a nivel mundial (OMS, 2017a; OMS, 2017b).

\section{Aire}

La concentración premeditada de las actividades productivas económicas y sociales emplazadas en la ciudad, es directamente proporcional a la cantidad de emisiones de gases de efecto invernadero, mismas que inducen de manera paradójica el caos urbano en el aire y en la salud humana. Las principales actividades que generan contaminación atmosférica se vinculan a los procesos y acciones llevadas a cabo en el cuerpo urbano, el cual es responsable de la emisión del 70\% del dióxido de carbono y del incremento de la quema de combustibles fósiles en un 500\% de 1950 a 2005 (ONU-Habitat, 2016, p. 16): la industria, la energía, el transporte, la generación de electricidad, los desechos sólidos urbanos municipales y la planificación urbana misma, son algunos ejemplos de ello. La contaminación del aire por efecto de las emisiones de gases derivadas de la acción urbana capitalista, es considerada de primordial importancia para la salud urbana, pero al mismo tiempo es un indicador de la salud humana; para el año 2016 se estimó que la contaminación atmosférica en áreas urbanas y rurales fue responsable de 4.2 millones de defunciones prematuras cada año, y el cálculo reciente es que la contaminación del aire interior por combustibles sólidos y 
del aire exterior por el uso de combustibles fósiles en el sector energético, transporte e industria, se atribuyen cerca de 3.1 millones de muertes prematuras en el planeta cada año, concentrando casi la mitad de estas enfermedades en el sur subdesarrollo. Dichos padecimientos incluyen infecciones respiratorias, enfermedades cardiovasculares, cáncer de pulmón, accidentes cerebrovasculares así como neuropatías crónicas y agudas como el asma (OMS, 2020; OMS, 2018). Las emisiones son un riesgo medioambiental principalmente en las ciudades, lugar donde se genera una cantidad exponencial derivada de las actividades económicas productivas, y la mortalidad asociada es principalmente por la exposición a partículas PM 2.5, es decir, partículas iguales o menores a 2.5 micrones de tamaño, suficientes para causar directamente enfermedades cardiovasculares, respiratorias y hasta cáncer (OMS, 2018). Los cálculos de la Organización Mundial de la Salud aluden que el $58 \%$ de las muertes prematuras asociadas fueron por cardiopatías isquémicas y accidentes cerebrovasculares, $18 \%$ por efectos de enfermedad pulmonar obstructiva crónica e infecciones respiratorias agudas, y el $6 \%$ por cáncer de pulmón (OMS, 2018). En otras palabras, la contaminación del aire corresponde a la calidad del medio ambiente y a la calidad de la salud urbana, misma que será un espejo reflectante de la salud de las personas que estén en contacto con ese medio biofísico.

\section{Suelo}

El ser humano desde su aparición ha vuelto al uso del suelo una necesidad intrínseca por el hecho de que su naturaleza, pero principalmente por el efecto de la fuerza gravitacional le permita desarrollarse sobre la superficie terrestre. El uso y contaminación del suelo a menudo suelen ser ignorados, pero representan uno de los peores escenarios de los últimos años; si bien el aprovechamiento del suelo es preponderante para el funcionamiento de la perspectiva neoliberal, la discusión mundial se centra en el suelo como sumidero y receptor de los desechos de cualquier actividad productiva. Las principales fuentes de origen de la contaminación ya sean puntuales o difusas son los químicos utilizados para la elaboración de mercancías, desechos domésticos, ganaderos, y municipales (aguas residuales), agroquímicos y derivados del petróleo (fertilizantes y plaguicidas), deposición atmosférica por fundición, transporte, combustión incompleta de sustancias, y hasta accidentes nucleares entre las más importantes. El tema se considera abandonado debido principalmente a la ausencia de datos científicos robustos que den certeza de la cantidad de contaminación hacia el suelo; uno de los cálculos a nivel global de la contaminación del suelo se llevó a cabo en la década de los 90's a cargo del Centro Internacional de Referencia e Información sobre Suelos (ISRIC) junto al Programa de las Naciones Unidas para el Medio Ambiente (PNUMA), estimando 22 millones de hectáreas afectadas por dicha contaminación. Actualmente, los países desarrollados encabezan la tarea por la generación de información, por lo cual las estimaciones anteriores podrían ser consideradas de una magnitud menor; el ministro de protección ambiental de China menciona que 19\% de sus suelos agrícolas están contaminados; en la zona económica europea y países colaboradores de los Balcanes Occidentales se estiman 3 millones de emplazamientos 
potencialmente contaminados; poco más de 1,300 emplazamientos se catalogan como contaminados en los Estados Unidos de América; en Australia se calcula en 80, 000 los emplazamientos contaminados. Por el contrario, no existe información confiable y suficiente en las regiones más pobres del mundo para cuantificar la magnitud de la contaminación del suelo (Rodríguez et al., 2019).

Lo que es un hecho, son las implicaciones en la salud del medio ambiente y su correlación con la salud humana. En general, directa e indirectamente una persona se encuentra en riesgo por la contaminación del suelo a través de diferentes vías: ingesta de animales o plantas que han acumulado cantidades importantes de sustancias contaminantes, exposición de la piel al hacer uso de espacios expuestos, inhalación de partículas que han sido vaporizadas así como la contaminación secundaria del agua y aire. Asimismo, los agentes patógenos en el suelo se vuelven una amenaza que contamina los alimentos, representando un riesgo importante para la salud humana, siendo el $24 \%$ de la población del planeta que presenta infecciones causadas por helmintos (parásitos en forma de gusano) los cuales causan desequilibrios nutricionales y anemias graves; se calcula también, que poco más de 200 enfermedades incluyendo las comunes como la diarrea y las graves como el cáncer, tienen una relación directa con la ingesta de alimentos contaminados. Por otro lado, el suelo contaminado con elementos químicos tóxicos en relación con la producción de alimentos es un problema real, ya que los múltiples metales presentes en el suelo son absorbidos por las raíces de las plantas, siendo el cadmio y plomo los más tóxicos para el humano (Rodríguez et al., 2019).

\section{Breve descripción del caos del trabajo y la fuerza de trabajo}

A través del crecimiento en el tiempo y de la expansión en el espacio, el modo de producción capitalista ha roto fronteras y se ha vuelto un sistema global que succiona plusvalía y renta hasta el último rincón de la tierra. El surgimiento de la etapa industrial ha traído una transformación social que se adecua a las necesidades del capital, particularmente dependiendo de la fuerza de trabajo, bienestar y la vida misma de un nutrido ejército de reserva que pierde y gana valor en el proceso. La fuerza de trabajo de los obreros se define como "condición personal de la producción", la cual se considera una "mercancía falsa o ficticia", ya que al contrario de las demás mercancías, la fuerza de trabajo no es producida ni reproducida para su venta en el mercado mundial; es imposible arrancarla de sus propietarios y no puede circular como billetes. Paradójicamente, la fuerza de trabajo no tiene valor de cambio, pues si el mercado mundial les otorgara el poder a los obreros de ser tratados como una mercancía invaluable, estos deberán ser considerados como si tuviesen valor, un alto valor que deberá ser retribuido. Por el contrario, el capital solo le otorga a la fuerza de trabajo, el valor de cambio necesario en el momento y espacio preciso según convenga, y esto sucede cuando se le hace notar a los trabajadores que su fuerza de trabajo tiene valor, lo cual induce una "autovaloración" indispensable para el aprovechamiento de esa fuerza de trabajo en vías de acumular. Sin embargo, desde el posicionamiento del obrero, el capital le resta valor cuando el contrato social capitalista corresponde al 
salario mínimo necesario que garantice la disposición de las condiciones de ínfima miseria de dicha fuerza de trabajo (O'Connor, 1998, pp. 175-180).

Dentro del contrato social entre un obrero y un capitalista, los conceptos "trabajo" y "fuerza de trabajo" son determinantes tanto para la acumulación de riqueza de los capitalistas, como el bienestar y hasta la vida misma de los obreros. Visto desde la postura neoliberal, plantear que el obrero vende su trabajo y no su fuerza de trabajo, significa que en el contrato social el obrero recibe una remuneración en forma de salario, mientras que el capitalista se beneficia por su capital, significando igualdad de derechos entre las dos partes, por lo que no existe explotación del hombre por el hombre. Por el contrario, al plasmar la firma del contrato social, el obrero no vende su trabajo pues este no ha comenzado a trabajar, sino que vende su capacidad de trabajo o fuerza de trabajo, siendo el capitalista el que determina como utilizarla según convenga, extrayendo plusvalía de dicha capacidad, teniendo implícita la explotación del hombre por el hombre (Mitropolski et al., 1985). Bajo estas premisas, el capitalista succiona plusvalía cuando los obreros trabajan más tiempo del requerido para crear el valor necesario de los medios indispensables que cubran sus mínimas necesidades (alimentación, ropa, calzado, vivienda etc.), o dicho en otras palabras, el capitalista solo retribuye al obrero un salario equivalente al tiempo y trabajo empleado del valor del producto que mantenga latente su condición de escasez, por lo que el tiempo y trabajo restante se lo apropia el capitalista, cerrando así un ciclo enmascarado de explotación incesante del hombre por el hombre. Por lo tanto, el capitalista solo considera productivo aquel trabajo del que pueda extraer mayor plusvalía, sin importar llevar al límite las formas de explotación que conducen a la miseria, la morbilidad y la muerte (Mitropolski et al., 1985, pp. 221-231).

El primer método se denomina "plusvalía absoluta", donde es preciso elevar la cuota de tiempo trabajado o jornada de trabajo, sin importar presionar a los obreros hacia la enfermedad o muerte. Gracias a las múltiples e intensas luchas de la clase obrera, por las altas tasas de morbilidad y mortalidad derivadas de brutales jornadas de trabajo que alcanzaban las 16 horas al día, en Inglaterra la jornada laboral se limitó a 12 horas a mediados del siglo XIX y 10 horas para 1901, y para el caso de Rusia fue en 1897 que la jornada disminuyó a 11.5 horas, hasta lograr las 8 horas actuales de trabajo (Mitropolski et al., 1985, p. 231; Hartman, 2008, p. 357). De hecho, en los primeros días de la revolución industrial, los capitalistas mostraron ser indiferentes con la salud de los obreros; las mujeres y los niños en las hilanderías proveían el trabajo más barato y abundante, a pesar que los efectos fueran adversos a sus condiciones óptimas de desarrollo; en Gran Bretaña por ejemplo, para 1871 los inspectores de la "ley de pobres" dejaban en claro que los niños urbanos más pobres casi nunca rebasaban los $1.25 \mathrm{~m}$ de altura ,o bien, un perímetro torácico de 0.75 metros a los 15 años (Hartman, 2008, p. 357). Se registra que en las primeras cuatro décadas del siglo XIX, ni siquiera el $10 \%$ de la población urbana gozaba de buena salud, y la tasa de mortalidad infantil alcanzaba el doble y algunas veces el triple respecto a las condiciones rurales, e incluso 
existen relatos de malformaciones entre la población obrera; se estima que el $20 \%$ de la mortalidad total se le adjudicaba a la tisis (tuberculosis), enfermedad asociada a la pobreza y la densidad poblacional (Thompson, 2012, p. 360). Tan solo en el distrito de Sheffield entre 1837 y 1842 , se registraron 11, 944 muertes destacando enfermedades como la tisis (1604), convulsiones (919), inflamación de los pulmones (874), decaimiento físico (800), accidentes (618), fiebre escarlatina (550), debilidad (519), dentición (426), infección intestinal (397), infección cerebral (351), consunción (346), sarampión (330), viruela (315), tos ferina (287), inflamaciones diversas (280), fiebre común (255), asma (206), garrotillo (166), parálisis (107) y afección hepática (106) (Thompson, 2012, pp. 361-362). Sin embargo, en palabras del doctor Holland, médico del hospital general de Sheffield:

[...] las muertes de cientos de personas de esta ciudad se deben atribuir a una carencia de las cosas indispensables para vivir. Puede que mueran de enfermedad, pero esta es ocasionada por el hecho de vivir en la pobreza, conjugada con el excesivo esfuerzo en el trabajo. (Thompson, 2012, p. 362)

Es así que el burgués controla la fuerza de trabajo a través de la competencia por encontrar los mejores empleos, sin importar rebasar los límites del esfuerzo humano, privilegiando al personal más eficiente considerando características como género, raza, tribu, lengua, política, creencias religiosas y orientación sexual, con el fin de ejercer una presión constante sobre los salarios (Harvey, 2012).
El segundo método de extracción de plusvalía después de reducir abruptamente la jornada laboral se denomina "plusvalía relativa", el cual consiste en elevar los niveles de explotación reduciendo el "tiempo de trabajo necesario" y aumentar el "tiempo de trabajo adicional" (apropiado por el capitalista), es decir, aumentar la productividad de trabajo por acción de la eficiencia y mejores rendimientos, con el fin de reducir el tiempo requerido del obrero para crear el valor necesario de los mínimos medios de su existencia, y aumentar, o en todo caso no reducir la cuota de trabajo adicional. Por lo que el grado de explotación será mayor, aunque la jornada laboral se haya reducido (Mitropolski et al, 1985, pp. 231-232).

Por efecto de la plusvalía absoluta y relativa, se necesita de una base abundante y concentrada de mano de obra en un espacio urbano para la acumulación del capital, que a diferencia del campo, promete las mejores condiciones de vida, falacia. Antes del año 1800 , aún el $70 \%$ de la población del planeta vivía en el campo y $30 \%$ en las ciudades, pero con el proceso de industrialización, a comienzos de 1800 el $2.2 \%$ de la población europea ya vivía en ciudades de más de 100,000 habitantes, pero no es hasta 1900 que $40 \%$ de la población se concentraba en ciudades de más de 100,000 personas (Munizaga, 2005, p.160). En la actualidad, el capital tiene a su disposición poco más de 7,000 millones de habitantes de los cuales poder extraer plusvalía: hasta el año 2020, el capitalismo tiene a su servicio a 3,491, 992,753 personas económicamente activas en todo el planeta (Banco Mundial, 2020b), y al resto como una jugosa reserva: al parecer, 
desde una perspectiva neoliberal, extraer el "tiempo de trabajo adicional" de la fuerza de trabajo del total de la población mundial, suena como un sucio pero jugoso negocio, que tiene como autor intelectual al medio urbano. De hecho, la estructura de las ciudades contemporáneas compite por un status que aplaste la estructura rural, aunque esto signifique perder de vista la escala y el ritmo de crecimiento de los emplazamientos de las periferias, los cuales crecen en desorden, por casualidad y algunas veces al azar; las ciudades de algunos países del Sur parecieran no tener estructura, avanzando solo con patrones irregulares y heterogéneos en busca de consolidación, incentivando el desorden urbano y aumentando los índices de pobreza de quienes las habitan, dando paso a la acumulación de condiciones de miseria (Davis, 2006); el 54\% de la población mundial vive en las ciudades, demostrando una tasa de crecimiento del año 2010 al 2015 del 2.05\%, siendo los países de altos ingresos los que representan las tasas más bajas con un $0.76 \%$, y por el contrario, los países con bajos ingresos las más altas tasas de crecimiento con un $3.77 \%$ en dicho periodo (ONU-Habitat, 2016, p. 7). Justamente hasta 2001, 924 millones de personas equivalente al $31.6 \%$ de la población mundial vivía en asentamientos irregulares, ahora denominados barrios pobres, y cerca de 880 millones de personas urbanas para 2014 (ONU-Habitat, 2016, p. 17).

En síntesis, la concentración de un ejército de reserva abundante, pobre, pero técnicamente eficiente cuando se le requiera, es un requisito fundamental para la operación de un cuerpo urbano saludable para los capitalistas, pero enfermo para los obreros.

\section{Caos capitalista asociado a la salud urbana y morbilidad urbana}

Las barreras, contradicciones o límites al desarrollo económico forman parte de una paradoja capitalista, configurada cuidadosamente con pinceladas en el espacio urbano. Particularmente, los límites de la dominación de la naturaleza se relacionan con el fin del desarrollo de las fuerzas productivas y modos de producción, encaminando a la civilización hacia un fenómeno de "basurero urbano inevitable" que se sustenta con una base histórica robusta; las condiciones de desarrollo económico propician la contaminación y la ausencia de recursos naturales, pulverizando su base de reproducción y enfermando al cuerpo urbano y humano, a punto del colapso. Incluso, es una falacia plantear que el desarrollo técnico e innovación tecnológica son respuesta a la ausencia de recursos naturales, ya que cualquier sistema tecnológico requiere de la naturaleza para su funcionamiento (Schoijet, 2008).

Los investigadores ecológicos han utilizado la perspectiva teórica de la "grieta metabólica" de Marx, para estudiar las contradicciones capitalistas que se desarrollan por efecto de la construcción y emplazamiento del ente urbano: estos incluyen los límites del planeta, el metabolismo del carbono, el agotamiento del suelo, la producción de fertilizantes, el metabolismo oceánico, la explotación indiscriminada de la pesca, la desforestación, los incendios forestales, los ciclos hidrológicos, la mega minería a cielo abierto, la cría de ganado, los agro-combustibles, la apropiación de tierras a nivel mundial, así 
como la contradicción entre la ciudad y el campo. La "grieta metabólica" es una teoría de la crisis ecológica o fractura por la permanente dependencia de la sociedad humana y sus condiciones de existencia orgánica, lo cual, asociado a la producción mercantil capitalista, es interpretado como una contradicción insuperable, cuyas implicaciones pueden comprenderse con base en una teoría más amplia, la del "metabolismo entre la naturaleza y la sociedad" (Bellamy Foster, 2010).

La interacción metabólica entre la naturaleza y la sociedad humana, no presupone que el hombre existe como un ente completamente independiente de la naturaleza, o fuera de ella, ni tampoco que la naturaleza es completamente independiente del hombre. Por el contrario, a pesar del inevitable proceso donde los seres humanos transforman el medio ambiente biofísico a través de su producción, estos no deben hacerlo como les plazca, sino bajo las condiciones heredadas de la historia natural y social, garantizando la dinámica básica de la vida y la existencia material (Foster, 2010). Por lo tanto, cuando los patrones heredados se llevan al límite y rompen, ocurren disturbios en el medio ambiente urbano que ha sido creado para las circunstancias de producción y acumulación, generando "externalidades negativas" principalmente por el aprovechamiento intensivo de recursos naturales y la generación sin freno de contaminación, y en general, por la presión de los medios de producción, mismos que hacen las veces de indicadores de la salud urbana directamente proporcional a la salud humana. El reflejo del caos medioambiental (aprovechamiento intensivo de recursos y contaminación del agua, aire y suelo), el caos de la fuerza de trabajo (extracción de plusvalía) y el caos del capital (generación y acumulación de capital presionando a los dos anteriores), se expresan en la mortalidad y morbilidad de las ciudades capitalistas en todo el planeta, o ¿será acaso que en algún rincón inexplorado existirá un modelo de ciudad comunitaria o ciudad no-capitalista que no contemple los principios de extracción de plusvalía y renta, o que no haya sido afectada o bien subsumida por el oleaje económico mundial? De no ser así, tan solo con el desarrollo de los conceptos estructurales clásicos del funcionamiento del modo de producción actual, poco podría dudarse que la categoría caos de los medios de producción es semejante a la salud urbana que condiciona la salud o enfermedad de quienes la habitan. De hecho, cuando se revisan los principales padecimientos que causan muerte en el planeta, teóricamente resulta imposible no asociarlas directa o indirectamente con alguna categoría del caos de los medios de producción, ver Figura 1.

Particularmente, el caos es diferenciado según la región y el nivel de ingresos de cada país, siendo directamente proporcional a los padecimientos que causan en sus habitantes; por ningún motivo el caos urbano deja de estar presente en la morbilidad o mortalidad humana, pues este se correlaciona con las actividades emplazadas en múltiples territorios urbanos que son pensados para generar riqueza y pobreza al mismo tiempo.

Las tasas de morbi-mortalidad son relativamente bajas cuando los entes urbanos ofrecen óptimas condiciones de vida para sus habitantes, incluyendo abastecimiento de agua potable, gestión de residuos, menores niveles de contaminación, una vivienda digna 
Figura 1 - 10 principales causas de muerte en el planeta (años 2000 y 2016)

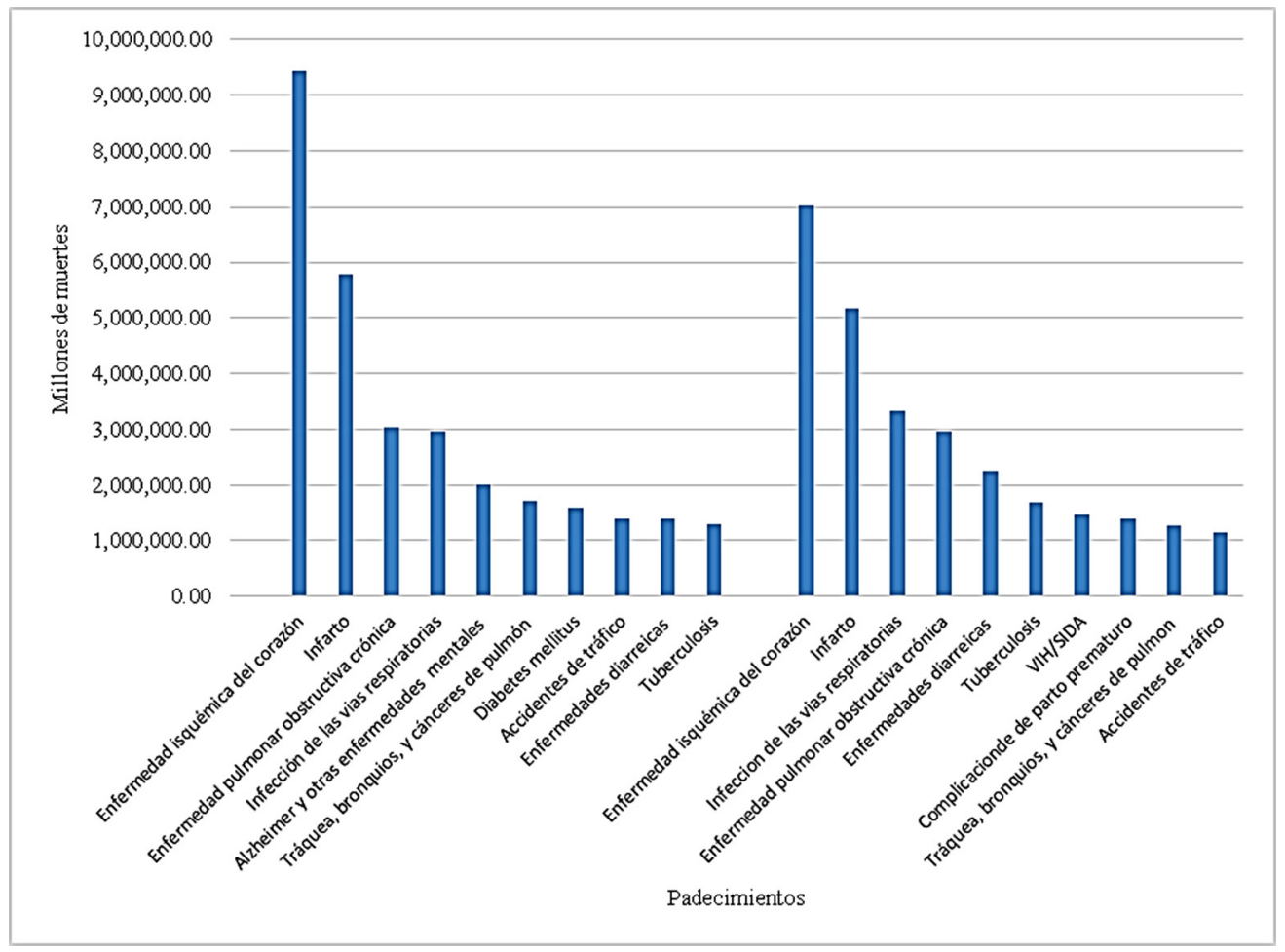

Fuente: elaboración propia según datos de World Health Organization, 2018a.

y sobretodo una estructura socioeconómica que garantice ingresos que les permitan cubrir sus necesidades básicas como el alimento, pero cuando estas mínimas condiciones se ausentan, es inminente el caos urbano enfocado a su status de morbilidad, localizado principalmente en los países de ingresos medios y bajos, donde no solo se concentra la mayoría de los pobres urbanos del mundo, sino donde se agudiza la pobreza, la exclusión y la desigualdad; se calcula que en las ciudades de los países subdesarrollados, 1 de cada 3 personas vive en asentamientos irregulares, que al no pagar impuestos, se ganan el derecho de ser relegados y no merecer servicios de dotación de agua, saneamiento, salud o educación, acciones que sin duda se asocian a la generación de múltiples enfermedades. Los hogares urbanos sin servicios básicos como disposición de agua potable y saneamiento, se relacionan con el aumento en las tasas de diarrea en niños urbanos menores de 5 años; el hambre y la malnutrición en los ámbitos urbanos se asocia no solo a la seguridad 
alimentaria, sino a la consecuencia de los riesgos ambientales y la precariedad de las viviendas, o en todo caso, al menor poder adquisitivo y la disponibilidad o alcance de mercancías que no precisamente inducen una alimentación saludable; la ausencia de higiene y saneamiento en los asentamientos urbanos irregulares aumentan el riesgo y la probabilidad de que un niño contraiga diarrea, infección aguda en el aparato respiratorio, e incluso, la propagación exponencial del paludismo y cualquier otra enfermedad transmitida por vectores, por efecto de la mala gestión de los residuos o la falta de agua potable constante (Waddington, 2010). Si bien las enfermedades infecciosas transmisibles son preponderantes en los ambientes urbanos, recientemente a los problemas de salud poblacional urbana se suman las enfermedades no transmisibles y las afecciones crónicas; enfermedades como la plaga neumónica, la gripe y la tuberculosis, se contagia y propaga fácilmente en aeropuertos, aviones, y en cualquier medio de transporte masivo; la poliomielitis se ha extendido por el mundo, y la ciudades son preponderantes para su propagación, por lo que las ciudades son tanto el medio como el fin para la incubación, desarrollo y propagación de nuevas enfermedades; se considera que el virus del VIH/Sida es una enfermedad predominantemente urbana, pues Onusida calcula que su prevalencia es casi dos veces mayor en las zonas urbanas que las rurales, y tan solo en las ciudades del África Subsahariana, las mujeres son las que tienen mayor riesgo para contraer el virus, sumándole el consumo de drogas por vía intravenosa que también es más común en las ciudades. El dengue, es sin duda uno de los ejemplos donde las condiciones urbanas y la ciudad misma puede propiciar la próxima pandemia, pues la ciudad tiene la cualidad de otorgar medios de incubación inesperados para aquellos oportunistas Ilamados mosquitos; se calcula que unos 1,500 millones de personas urbanas de países desarrollados se encuentra en riesgo por estar en contacto con altas concentraciones de contaminación atmosférica por encima de los límites permisibles, y particularmente se estima que las emisiones de los vehículos automotores y las fabricas son responsables del $8 \%$ de las muertes por cáncer de pulmón, $5 \%$ de las muertes cardiopulmonares y $3 \%$ de las muertes por infección respiratoria; debido a la constante presión que presupone vivir en las ciudades, el ritmo urbano contribuye al incremento de los trastornos mentales y la angustia, pues se calcula que del 12 al 51\% de los adultos urbanos padecen depresión. Por último, debido al necesario implemento de las carreteras y la comercialización de medios de transporte individual que son ejes de la urbanización desorganizada en países subdesarrollados, son causantes de muertes por accidentes de tránsito, los cuales se calculan en 1.3 millones de muertes en las carreteras y dejando hasta 50 millones de personas heridas, e incluso se estima que por cada muerte que se produce, entre 20 a 30 personas quedan discapacitadas (Waddington y Lautrédou, 2010).

Por tanto, el estrujamiento de los medios de producción inmortalizados en las ciudades, hacen las veces de los medios necesarios para la acumulación de la riqueza, pero al mismo tiempo las barreras, contradicciones y límites que amenazan la supervivencia humana. Presionar a los recursos naturales hasta su límite (caos medioambiental), obliga a romper las barreras del equilibrio natural, siendo una 
Figura 2 - Top 10 principales causas de muerte en el planeta por región de la OMS y su asociación estructural

\begin{tabular}{|c|c|c|c|c|c|}
\hline \multirow{2}{*}{ Región } & \multirow{2}{*}{ Causa de muerte } & \multirow{2}{*}{ Muertes } & \multicolumn{3}{|c|}{ Asociación teórica estructural directa } \\
\hline & & & $\begin{array}{c}\text { Caos medio } \\
\text { ambiental }\end{array}$ & $\begin{array}{c}\text { Caos de la } \\
\text { fuerza de trabajo }\end{array}$ & $\begin{array}{c}\text { Caos del } \\
\text { capital }\end{array}$ \\
\hline \multirow{10}{*}{ Africa } & Infección de las vias respiratorias & 916.900 & $\mathrm{x}$ & $\mathrm{x}$ & \\
\hline & VH/SIDA & 718.800 & & & $\mathrm{x}$ \\
\hline & Enfermedades diarreicas & 652.800 & $\mathrm{x}$ & $\mathrm{x}$ & \\
\hline & Enfermedad isquémica del corazón & 511.900 & $\mathrm{x}$ & $\mathrm{x}$ & \\
\hline & Malaria o Paludismo & 408.100 & $\mathrm{x}$ & $\mathrm{x}$ & \\
\hline & Tuberculosis & 405.500 & & & $\mathrm{x}$ \\
\hline & Infartos & 373.500 & $\mathrm{x}$ & $\mathrm{x}$ & \\
\hline & Complicaciones de parto prematuro & 343.700 & & $\mathrm{x}$ & $\mathrm{x}$ \\
\hline & Asfixia congénita y traumatismo congénito & 322.800 & & & \\
\hline & Accidentes de tráfico & 283.500 & & $\mathrm{x}$ & $\mathrm{x}$ \\
\hline \multirow{10}{*}{ América } & Enfermedad inquémica del corazón & 1.091 .300 & $\mathrm{x}$ & $\mathrm{x}$ & \\
\hline & Infartos & 436.700 & & $\mathrm{x}$ & \\
\hline & Enfermedad pulmonar obstructiva crónica & 368.200 & $\mathrm{x}$ & $\mathrm{x}$ & \\
\hline & Alzheimer y otras enfermedades mentales & 351.700 & & & $\mathrm{x}$ \\
\hline & Diabetes mellitus & 342.600 & & $\mathrm{x}$ & $\mathrm{x}$ \\
\hline & Infección de las vias respiratorias & 310.900 & $\mathrm{x}$ & $\mathrm{x}$ & \\
\hline & Tráquea, bronquios y cánceres de pulmón & 254.000 & $\mathrm{x}$ & & \\
\hline & Enfermedades renales & 181.000 & & $x$ & $\mathrm{x}$ \\
\hline & Violencia interpersonal & 177.800 & & $\mathrm{x}$ & $\mathrm{x}$ \\
\hline & Accidentes de tráfico & 157.300 & & $\mathrm{x}$ & $\mathrm{x}$ \\
\hline \multirow{10}{*}{ Sureste de Asia } & Enfermedad isquémica del corazón & 2.234 .000 & $\mathrm{x}$ & $\mathrm{x}$ & \\
\hline & Infartos & 1.250 .000 & & $\mathrm{x}$ & \\
\hline & Enfermedad pulmonar obstructiva crónica & 104.400 & $\mathrm{x}$ & $x$ & \\
\hline & Infección de las vias respiratorias & 783.000 & $\mathrm{x}$ & $\mathrm{x}$ & \\
\hline & Tuberculosis & 651.000 & & & $\mathrm{x}$ \\
\hline & Enfermedades diarreicas & 526.000 & $\mathrm{x}$ & $\mathrm{x}$ & \\
\hline & Diabetes mellitus & 503.000 & & $\mathrm{x}$ & $\mathrm{x}$ \\
\hline & Accidentes de tráfico & 409.000 & & $\mathrm{x}$ & $\mathrm{x}$ \\
\hline & Cirrosis en el higado & 402.000 & & $\mathrm{x}$ & $\mathrm{x}$ \\
\hline & Enfermedades renales & 376.000 & & & $\mathrm{x}$ \\
\hline \multirow{10}{*}{ Europa } & Enfermedad isquémica del corazón & 2.342 .000 & $\mathrm{x}$ & $\mathrm{x}$ & \\
\hline & Infartos & 986.000 & & $\mathrm{x}$ & \\
\hline & Alzheimer y otras enfermedades mentales & 481.000 & & & $\mathrm{x}$ \\
\hline & Tráquea, bronquios y cánceres de pulmón & 419.000 & $\mathrm{x}$ & & \\
\hline & Enfermedad pulmonar obstructiva crónica & 349.000 & $\mathrm{x}$ & $\mathrm{x}$ & \\
\hline & Cáncer de colon y recto & 265.000 & $\mathrm{x}$ & $\mathrm{x}$ & $\mathrm{x}$ \\
\hline & Infección de las vias respiratorias & 245.000 & $\mathrm{x}$ & $\mathrm{x}$ & \\
\hline & Diabetes mellitus & 179.000 & & $\mathrm{x}$ & $\mathrm{x}$ \\
\hline & Cirrosis en el higado & 178.000 & & $x$ & $\mathrm{x}$ \\
\hline & Cáncer de mama & 165.000 & & & $\mathrm{x}$ \\
\hline \multirow{10}{*}{$\begin{array}{l}\text { Este del } \\
\text { Mediterráneo }\end{array}$} & Enfermedad isquémica del corazón & 834.700 & $x$ & $\mathrm{x}$ & \\
\hline & Infartos & 326.400 & & $\mathrm{x}$ & \\
\hline & Infección de las vias respiratorias & 220.900 & $\mathrm{x}$ & $\mathrm{x}$ & \\
\hline & Complicaciones de parto prematuro & 180.700 & & $\mathrm{x}$ & $\mathrm{x}$ \\
\hline & Violencia colectiva e intervenciones legales & 154.200 & & $\mathrm{x}$ & $\mathrm{x}$ \\
\hline & Diabetes mellitus & 130.800 & & $\mathrm{x}$ & $\mathrm{x}$ \\
\hline & Cirrosis en el higado & 129.500 & & $\mathrm{x}$ & $\mathrm{x}$ \\
\hline & Accidentes de tráfico & 128.000 & & $\mathrm{x}$ & $\mathrm{x}$ \\
\hline & Asfixia congénita y traumatismo congénito & 116.500 & & & \\
\hline & Enfermedades diarreicas & 116.400 & $\mathrm{x}$ & $\mathrm{x}$ & \\
\hline \multirow{10}{*}{$\begin{array}{l}\text { Pacífico } \\
\text { Occidental }\end{array}$} & Infartos & 2.393 .000 & & $\mathrm{x}$ & \\
\hline & Enfermedad isquémica del corazón & 2.391 .000 & $x$ & $\mathrm{x}$ & \\
\hline & Enfermedad pulmonar obstructiva crónica & 104.000 & $\mathrm{x}$ & $\mathrm{x}$ & \\
\hline & Tráquea, bronquios y cánceres de pulmón & 789.000 & $\mathrm{x}$ & & \\
\hline & Alzheimer y otras enfermedades mentales & 671.000 & & & $\mathrm{x}$ \\
\hline & Cáncer de higado & 515.000 & & $\mathrm{x}$ & $\mathrm{x}$ \\
\hline & Infección de las vias respiratorias & 470.000 & $\mathrm{x}$ & $\mathrm{x}$ & \\
\hline & Cáncer de estómago & 412.000 & & $\mathrm{x}$ & $\mathrm{x}$ \\
\hline & Accidentes de tráfico & 343.000 & & $\mathrm{x}$ & $\mathrm{x}$ \\
\hline & Enfermedades cardiacas hipertensivas & 313.000 & $\mathrm{x}$ & $\mathrm{x}$ & $\mathrm{x}$ \\
\hline
\end{tabular}

Fuente: elaboración propia según datos de World Health Organization, 2018a. 
contradicción expresada no solo en escasez de recursos y contaminación, sino altas tasas de morbilidad y mortalidad asociadas; presionar la fuerza de trabajo hasta su límite (caos de la fuerza de trabajo), buscando diferentes mecanismos de extracción de plusvalía para trabajar más y pagar menos, sin duda se expresan en múltiples formas de enfermarse hasta morir; asimismo, alimentar la insaciable irracionalidad económica de "dinero en busca de más dinero" (caos del capital) es el inicio y cierre del ciclo de la acumulación del capital presionando a los dos anteriores. En otras palabras, las tres categorías sometidas progresivamente al caos intentan ser una ruta crítica que analice los problemas de salud humana en las ciudades desde su perspectiva teórica-estructural, pues presionar un medio de producción hasta secarlo resulta desastroso, hacerlo con los tres medios de producción, lo vuelve inevitablemente catastrófico, ver Figura 2.

\section{Salud urbana y morbilidad urbana: una aproximación conceptual}

La definición de salud como concepto ha sido sujeto de una serie de intervenciones a lo largo de la historia de las civilizaciones. La Real Academia Española por ejemplo, define salud como "estado en el que el ser orgánico ejerce normalmente todas sus funciones", aunado al "conjunto de las condiciones físicas en que se encuentra un organismo en un momento determinado". Por el contrario, cuando el hombre aún convivía en comunidades y el objetivo primordial era la supervivencia o la acción y efecto de sobrevivir, la salud se interpretaba como sinónimo de vida o al hecho de estar vivo. Actualmente, la Organización Mundial de la Salud (OMS) la define como el "estado de completo bienestar físico, mental y social, y no solamente la ausencia de afecciones o enfermedades" (Herrero, 2016). Asimismo, Lebel (2005) define a la salud de la siguiente manera:

La salud no es la ausencia de enfermedad. Está mejor definida como una participación armónica en los recursos del medio ambiente, que permiten a los individuos el desarrollo pleno de sus funciones y aptitudes. (Lebel, 2005, p. 8)

Con base en estas definiciones, los conceptos médicos bien podrían trasladarse analógicamente al funcionamiento del cuerpo urbano, que merma su condición cuando alguno de sus componentes no funciona correctamente, o al revés, que goza de salud cuando esos mismos componentes funcionan según lo previsto; sin embargo cuando estos componentes funcionan según lo previsto, significa una alta presión de los medios de producción hasta su límite y con ello daños colaterales en los más vulnerables, pues para ello fueron creados. Si trasladamos las definiciones médicas a una perspectiva urbana, la ciudad presenta indicadores estructurales que la hacen susceptible de ser un ente saludable por el hecho de estar vivo, o en su defecto, un ente enfermo sinónimo de estar muerto, pero su salud estaría mejor definida valorando el bienestar de sus componentes sociales, económicos y ambientales, símil a los físicos, mentales y sociales del cuerpo humano. No obstante, discutir los indicadores de forma predeterminada según las condiciones 
neoliberales, no resuelven el problema, ya que estas condiciones fueron concebidas para crear caos urbano y no ciudades saludables. Ahora bien, las condiciones reales de los componentes estructurales que la clasifican como ciudad saludable, o el mal funcionamiento de los mismos como ciudad enferma, literalmente inducen efectos inconmensurables y hasta imprevistos en sus habitantes, que bien pueden ser traducidos en salud en un extremo, así como morbilidad y muerte en el otro. En este sentido, nos encontramos ante la paradoja del ente urbano que intenta utópicamente alcanzar niveles de salud que contradicen su esencia misma de funcionamiento, pues seguir construyendo la idea de ciudades sostenibles sin dejar de lado la racionalidad económica neoliberal, nos condena a alcanzar los límites de los medios de producción (capital, tierra y trabajo) mismos que son amenazas civilizatorias.

Por lo tanto, el proceso de contaminación del medio ambiente biofísico (agua, aire y suelo), y en general, la contaminación con residuos en diferentes estados de la materia, bien podrían ser descritos como resultado de un incremento del síndrome urbano de amnesia residual aguda y miopía residual severa; definiendo síndrome como al conjunto de síntomas y afecciones que se presentan juntos y sugieren la presencia de cierta enfermedad o una mayor probabilidad de padecer de una enfermedad (Instituto Nacional del Cáncer, sin año), a diferencia que el enfermo no es el humano, sino la ciudad. Dicho padecimiento se centra principalmente en el juicio y la atención de los tomadores de decisiones y funcionarios públicos, particularmente cuando se trata de otorgar tratamiento a los residuos que brotan como pus de las llagas del cuerpo urbano. Si bien a estas alturas el desarrollo de las "funciones mentales superiores" del ser humano, originadas en el comunismo primitivo, tendrían que ser bastas para evitar acciones que causen algún daño al medio ambiente y al ser humano, al parecer no existe el suficiente desarrollo de la atención por parte de los funcionarios y tomadores de decisiones en cualquier parte del mundo, o peor aún, que esta capacidad es bloqueada de forma voluntaria e involuntaria, que indiscutiblemente al no prestar "atención" se priva del funcionamiento, efectividad y ejecución de las otras funciones del cerebro, incluyendo las ejecutivas, el razonamiento, el pensamiento, la conciencia, las emociones, el lenguaje, la memoria y el aprendizaje (Meza et al., 2003; Bodrova y J., Leong, 2004). Por lo que poco podría dudarse que los síntomas de este síndrome urbano incluyen corrupción severa, cinismo agudo, conciencia sin remordimiento, alteración del enfoque visual, inflamación de cuentas bancarias, pérdida de memoria de corto plazo, y una indiferencia crónica por el medio ambiente y los pobres, cánones indiscutibles de la lógica capitalista. Del mismo modo, la diversificación de la presión por mantener latente a un "ejército de reserva" urbano pobre, efectivo y abundante, sin duda se vinculan a crear las condiciones en el cuerpo urbano para someter y llevar al límite (en la medida de la resistencia del trabajador) al cuerpo humano, necesario para cada una de las actividades productivas sin importar incluso, que se enfermen o pierdan la vida. O por el contrario, alimentar la racionalidad voraz de unos cuantos por acumular riquezas y ganancias a costa de presionar a los dos medios de producción anteriores, es el principal indicador de la 
morbilidad del cuerpo urbano directamente proporcional al humano... el humano más pobre por supuesto. Es así que los indicadores estructurales de los medios de producción, si bien son diseñados para la acumulación de la riqueza sin importar los daños colaterales, utópicamente bien podrían hacer las veces de los indicadores para lograr la salud urbana, que al disminuir su intensidad lograrían ir pegando la "grieta metabólica" o armonizando la "relación hombre-naturaleza", abriendo camino no a una "segunda naturaleza", sino a la misma naturaleza que había perdurado por siglos. Los intentos de resarcir los daños con estrategias urbanísticas, arquitectónicas y medioambientales sin cambios estructurales sustanciales, no son otra cosa que intentar detener un ferrocarril con trozos pequeños de cinta adhesiva ecológica color verde, que no por ser ecológica o verde, detienen el impacto.

\section{Reflexiones preliminares}

La ciudad como esbozo del espacio construido ha tenido un objetivo claro en la historia, acumular para edificar. Sin embargo, los intentos de trazos son proporcionales a cada modo de producción, elaborando una caligrafía urbana diferenciada en respuesta a las necesidades que le permitan consolidar dicha racionalidad productiva. En la comunidad primitiva se desarrollan elementos que satisfacen el principio de resguardarse para sobrevivir, bosquejando elementos apegados a su característico modo comunitario de reproducción, mientras en el esclavismo ya se discute la ciudad como elemento de apropiación y acumulación, más allá de las necesidades fisiológicas humanas; por otro lado, si bien el feudalismo ya requería de una morfología urbana específica para la apropiación de tierras y mano de obra, no es hasta la aparición del capitalismo que con bolígrafos privados, la ciudad es dibujada para la apropiación y generación del caos de los medios de producción. El ente urbano capitalista es la materialización de dicha racionalidad irracional, reconocida como "su máxima expresión", y es el caos de los medios de producción el que permite una transfiguración que asigna a cada actividad, espacios materiales construidos, hasta otorgarle un cuerpo tangible, igual a un lienzo que expresa el aprovechamiento de los recursos naturales y que con sus manos moldea monumentos a la explotación de la mano de obra; de hecho, la morfología de cualquier cuerpo urbano capitalista o el diseño mismo de alguna extremidad urbana, corresponden a los principios de "producción, distribución y acumulación", que no solo plantean extraer hasta la última gota de plusvalía o renta de los medios de producción, sino que signifiquen "extracción-contaminación, fragmentación y destrucción", acciones inadmisibles que han transformado un comportamiento humano volviéndolo parte de su naturaleza. Es entonces que el capital expresa su poder en el territorio, emplazado en la proximidad de los medios de producción; el caos que provoca la diferenciación geográfica es el cimiento para que comience la acumulación del capital, por lo que la diversidad geográfica se vuelve una condición necesaria para esta acumulación, y si el caos no existe, debe crearse. Por tanto, si la producción y reproducción del espacio (urbanización), es el gran negocio del capitalismo por ser la 
máxima vía de acumulación de riqueza, y si la premisa básica del modo de producción capitalista es la acumulación de la misma con base en la explotación del hombre por el hombre, mientras extrae, consume y abarata los recursos que provee gratuitamente la naturaleza, ¿por qué sorprende que las ciudades sean enfermas?, ¿por qué asombra que millones que no acumulan se enfermen o mueran?. Es irónico, pues no es posible apaciguar el instinto de un depredador urbano concebido para rasgar, roer o masticar. De hecho, el origen de la concepción de una ciudad enferma a través del caos, nos lleva a discutir si la ciudad en su conjunto es creada para vivir en caos permanente, pese a que nos emita más de un par de falacias urbanas con soluciones paradójicamente insostenibles en busca de la tan ansiada salud urbana, pues dispersar el caos, no significa eliminarlo; incluso, son las corrientes arquitectónicas y urbanísticas sin sustento teórico, las que nos han encaminado hacia el capitalismo edificado, es decir, hacia la creación de miles de espacios y condiciones que respondan a las necesidades del mercado, como si los otros que no acumulan necesitaran más rascacielos, plazas o carreteras que consumen y contaminan los recursos indispensables para sobrevivir. Esta crítica urbana vista desde el análisis del funcionamiento de la ciudad a través del caos de los medios de producción, cuestiona la perspectiva urbana superficial, profundizando la discusión de la salud y morbilidad urbana con nulo sostén teórico de la ciudad como máxima promesa de los fines económicos, y sí como la expresión máxima de los fines económicos plasmados en un espacio llamado ciudad, que en última instancia requiere de su morbilidad como status fundamental de su reproducción. Además, la estructura urbana analítica permite abrir una lógica teórica cuyos elementos son los medios de producción asociados a su nivel de caos, vista como una posible aportación categorial que suma a la interpretación y resolución de un problema épocal que amenaza la supervivencia de aquellos que no acumulan. En otras palabras, el análisis del caos de los medios de producción desnuda los principios mismos por los que la ciudad es concebida, entendiendo la ciudad como resultado de un conjunto de mercancías, o mejor aún, donde la ciudad capitalista es la máxima mercancía. Por lo que es necesario cuestionarse: ¿̇será que la ciudad es la expresión máxima de superioridad que sepulta los derechos fundamentales de los que no poseen la riqueza?, ¿la ciudad, es quizá el engendro máximo de la desigualdad, por lo que el $46 \%$ de la población mundial se resiste a ser parte de ella?, ¿por qué seguir buscando respuestas efímeras en la ciudad y no respuestas sustanciales en lo rural-comunitario?, e incluso, ¿será acaso que las "condiciones naturales" nos dan para satisfacer un derecho masivo individual a la ciudad, en lugar de un derecho colectivo a lo rural-comunitario? 


\section{[I] https://orcid.org/0000-0002-3059-0959}

Universidad Autónoma del Estado de Morelos, Facultad de Arquitectura. Cuernavaca, Morelos, México.

futgio_mm7@hotmail.com

\section{[II] https://orcid.org/0000-0001-9970-1082}

Universidad Autónoma del Estado de Morelos, Facultad de Arquitectura. Cuernavaca, Morelos, México.

rafaelmoor@hotmail.com

\section{Referencias}

BANCO MUNDIAL (2020a). Pobreza: panorama general. Disponible en: https://www.bancomundial. org/es/topic/poverty/overview. Acceso en: 19 septiembre 2020.

(2020b). Población total y población activa. Disponible en: https://datos.bancomundial.org/ indicador/SP.POP.TOTL. Acceso en: 20 septiembre 2020.

BELLAMY FOSTER, J. (2010). Marx's Ecology. Materialism and nature. Monthly Review. Nova York, pp. 141-177.

BIFANI, P. (1997). El pensamiento económico y la relación desarrollo medio ambiente. En: BIFANI, P. Medio ambiente y desarrollo. México, Universidad de Guadalajara.

BODROVA, E.; LEONG, D. J. (2004). Herramientas de la mente: el aprendizaje de la infancia desde la perspectiva de Vygotsky. La adquisición de la mente y las funciones mentales superiores. México, Pearson Educación de México y Secretaria de Educación Pública. Disponible en: file:///C:/Users/ gio/Desktop/1.\%20Herramientas-de-La-Mente-ELENA-BODROVA1.pdf. Acceso en: 18 mayo 2020.

CAPEL, H. (2002). La morfología de las ciudades: I. Sociedad, cultura y paisaje urbano. Barcelona, Ediciones del Serbal.

DAVIS, M. (2006). Planeta de ciudades miseria. Espanha, Foca.

DUSSEL, E. (2016). 16 Tesis de economía política. Interpretación filosófica. México, Siglo XXI.

FAO (2016). Sitio web Aquastat. Organización de las Naciones Unidas para la Alimentación y la Agricultura. Disponible en: http://www.fao.org/nr/water/aquastat/data/query/index.html. Acceso en: 5 marzo 2020.

FURTADO, C. (2014). Teoría y política del desarrollo económico. México, Siglo XXI.

HARTMAN, C. (2008). Historia mundial del pueblo. Desde la edad de piedra hasta el nuevo milenio. Madri, Akal.

HARVEY, D. (2012). El enigma del capital y las crisis del capitalismo. Madri, Akal. 
HERRERO, J. S. (2016). Formalización del concepto de salud a través de la lógica: impacto del lenguaje formal en las ciencias de la salud. Disponible en: http://scielo.isciii.es/scielo.php?script=sci_ arttext\&pid=S1988-348X2016000200006\&Ing=es\&tlng=es. Acceso en: 12 junio 2020.

INSTITUTO NACIONAL DEL CÁNCER, (sin año). Publicaciones: diccionario de cáncer. Síndrome: Portal web del Instituto Nacional del Cáncer de los Institutos Nacionales de la Salud de EE.UU. Disponible en: https://www.cancer.gov/espanol/publicaciones/diccionario/def/sindrome. Acceso en: 2 junio 2020.

LEBEL, J. (2005). Salud. Un enfoque ecosistémico. Centro internacional de investigaciones para el desarrollo. Omega. Capítulo 1 y 2.

MARX, K. (2000). El capital. Critica de la economía política. México, Fondo de Cultura Económica.

(2008). Contribución a la crítica de la economía política. Espanha, Siglo XXI.

MEZA, E.; SORIANO, Á.; SOLÍS, O.; GARCÍA, S.; ZÁRATE, A. (2003). Funciones mentales, la actividad más evolucionada del cerebro humano. Revista de Especialidades Médico-Quirúrgicas. Disponible en: https://www.redalyc.org/articulo.oa?id=473/47380302. Acceso en: 12 junio 2020.

MITROPOLSKI, D.; ZUBRITSKI, Y.; KEROV, V. (1985). Manual de historia y economía. México, Quinto Sol, pp. 221-239

MUNIZAGA VIGIL, G. (2005). Las ciudades y su historia: una aproximación. México, Alfaomega.

O’CONNOR, J. (1998). Causas naturales. Ensayos de marxismo crítico. México, Siglo XXI.

OMS (2017a). Agua, saneamiento e higiene. Enfermedades y riesgos asociados a las deficiencias en los servicios de agua y saneamiento. Disponible en: http://www.who.int/water_sanitation_health/ diseases-risks/es/. Acceso en: 14 mayo 2020.

(2017b). Enfermedades diarreicas. Datos y cifras. Disponible en: http://www.who.int/es/newsroom/fact-sheets/detail/diarrhoeal-disease. Acceso en: 14 mayo 2020.

(2018). Calidad del aire y salud. Datos y cifras. Disponible en: https://www.who.int/es/newsroom/fact-sheets/detail/ambient-(outdoor)-air-quality-and-health. Acceso en: 22 mayo 2020.

(2020). Contaminación del aire. Disponible en: https://www.who.int/ipcs/assessment/public_ health/air_pollution/es/\#. Acceso en: 16 mayo 2020.

ONU-HABITAT (2016). Reporte ciudades del mundo 2016. Urbanización y desarrollo: futuros emergentes. Nairobi/Kenia, Programa de las Naciones Unidas para los asentamientos humanos (ONU-Habitat).

PIKETTY, T. (2014). El capital en el siglo XXI. México, Fondo de Cultura Económica.

PONTÓN, G. (2017). La lucha por la desigualdad. Una historia del mundo occidental en el siglo XVIII. Barcelona, Ediciones de Pasado y Presente.

RODRÍGUEZ-EUGENIO, N.; MCLAUGHLIN, M.; PENNOCK, D. (2019). La contaminación del suelo: una realidad oculta. Roma, FAO.

SARTELLI, E. (2013). La cajita infeliz. Un viaje marxista a través del capitalismo. Argentina, Ciecs.

SCHOIJET, M. (2008). Límites del crecimiento y cambio climático. México, Siglo XXI. 
TANURO, D. (2013). La crisis ecológica capitalista. Las fases del desarrollo de la crisis ecológica capitalista. Disponible en: http://old.sinpermiso.info/articulos/ficheros/tanuro.pdf. Acceso en: 30 febrero 2020.

THOMPSON, E. P. (2012). La formación de la clase obrera en Inglaterra. Espanha, Capitán Swing Libros.

UN WATER (2015). Informe de las Naciones Unidas sobre los recursos hídricos en el mundo 2015. Agua para un mundo sostenible. Disponible en: http://unesdoc.unesco.org/ images/0023/002322/232273e.pdf. Acceso en: 18 febrero 2020.

(2017). Informe Mundial de las Naciones Unidas sobre el Desarrollo de los Recursos Hídricos. Aguas residuales: El recurso desaprovechado. Paris, Unesco. Disponible en: http://unesdoc. unesco.org/images/0024/002471/247153e.pdf. Acceso en: 23 mayo 2020.

U.S. GEOLOGICAL SURVEY (2017). La ciencia del agua para escuelas. Distribución del agua de la tierra. U.S. Department of the Interior. Disponible en: https://water.usgs.gov/gotita/waterdistribution. html. Acceso en: 5 marzo 2020.

WADDINGTON, R. (2010). Urban risk to health. In: International Federation of Red Cross and Red Crescent Societies. World Disasters Report 2010. Focus on Urban Risk. Disponible en: https:// www.ifrc.org/es/publicaciones/world-disasters-report/informe-mundial-sobre-desastres/. Acceso en: 9 abril 2021.

WADDINGTON, R.; LAUTRÉDOU, G. (2010). Urban risk to health. In: International Federation of Red Cross and Red Crescent Societies. World Disasters Report 2010. Focus on Urban Risk. Disponible en: https://www.ifrc.org/es/publicaciones/world-disasters-report/informe-mundial-sobredesastres/. Acceso en: 9 abril 2021.

WORLD HEALTH ORGANIZATION (2018a).The global Health Observatory. Causes of death 2000-2016. Disponible en: https://www.who.int/data/gho/data/themes/topics/causes-of-death. Acceso en: 3 junio 2020.

WWF (2016). Informe planeta vivo. Resumen. Disponible en: http://www.wwf+.org.mx/quienes_ somos/informe_planeta_vivo/. Acceso en: 5 enero 2020. 
